\title{
Reconocimiento pretorio y jurisprudencial de la función social de los bienes destinados al uso público -res publicae in publico usu-1
}

\author{
Juan Miguel Alburquerque $2-3$
}

1 Este trabajo ha sido realizado en el marco del Proyecto I+D de Excelencia "Experiencia administrativa y medioambiental romana. Bienes públicos, medio ambiente y salubritas, urbanismo y delitos por actividad ilícita de los magistrados", Ref.: DER 2015-64317-P MINECO/FEDER, del Programa Estatal de Fomento de la Investigación Científica y Técnica de Excelencia del Ministerio de Fomento y Competitividad. Investigadores principales: Profesores Dres. Juan Miguel Alburquerque y Carmen Jiménez Salcedo.

2 Doctor en Derecho, Universidad Complutense, Madrid, España. Catedrático de Derecho Romano de la Universidad de Córdoba, Córdoba, España ${ }_{i}$ académico correspondiente de la Real Academia de Jurisprudencia y Legislación, vocal de la Sección Derecho Romano, Madrid, España. Correo-e: fd1alsaj@uco.es Fecha de recepción: 1 de julio de 2016. Fecha de modificación: 29 de agosto de 2016. Fecha de aceptación: 15 de septiembre de 2016. Para citar el artículo: Alburquerque, J. M. "Reconocimiento pretorio y jurisprudencial de la función social de los bienes destinados al uso público -res publicae in publico uso-", Revista digital de Derecho Administrativo, n. ${ }^{\circ} 17$, primer semestre, Universidad Externado de Colombia, 2017, pp. 141-161. DOI: http://dx.doi.org/10.18601/21452946.n17.09

3 Quiero expresar mi reconocimiento y agradecimiento al principal impulsor y director de los estudios concernientes a la experiencia administrativa, medioambiental y fiscal romana en España, Antonio Fernández de Buján, catedrático de Derecho Romano de la Universidad Autónoma de Madrid, académico de número de la Real Academia de Jurisprudencia y Legislación, e investigador principal desde hace más de dos décadas de varios proyectos compartidos de investigación en los que también he participado-ya ejecutados y publicados sobre esta materia-, así como director de varios libros específicos sobre el derecho administrativo histórico $(2005,2011,2013,2016)$. Asimismo es director de la prestigiosa Colección Dykinson "Monografías de Derecho Romano", "Sección Derecho Administrativo y Fiscal Romano" y "Sección Derecho Público y Privado Romano", con más de cincuenta monografías ya publicadas. 


\title{
RESUMEN
}

Nuestro propósito en esta contribución consistirá principalmente en reunir aquí de forma resumida un conjunto más o menos homogéneo de reflexiones jurídicas propias del ámbito de la experiencia administrativa romana, en relación al reconocimiento de la función social de las res publicae in publico usu, y la correspondiente tutela interdictal sobre lugares públicos. En este sentido, analizaremos especialmente los diferentes títulos (VII a XV) del libro 43 del Digesto donde aparecen recogidas las disposiciones interdictales objeto de nuestro estudio.

Palabras clave: Res publicae, res quae publico usui destinatae, publicatio, publicae in pecunia populi, in patrimonio populi, mari, litore, publicis locis, loca, itinere, viae, flumina, ripae.

\section{Pretorian and Jurisprudential Recognition of the Social Function of Property Designated for Public Use - Res publicae in publico usu}

\begin{abstract}
The purpose of this contribution will consist in providing a summary of a more or less homogeneous set of legal considerations from the Roman administrative experience in relation to the recognition of the social function of res publicae in publico usu, and the corresponding injunctive protection over public places. Therefore, we shall primarily analyze the different Titles (from VII to XV) of book 43 of the Digest, where these injunctive provisions, the object of our study, are set forth.
\end{abstract}

Keywords: Public Property, res publicae, res quae publico usui destinatae, publicatio, publicae in pecunia populi, mari, litore, publicis locis, loca, itinere, viae, flumina, ripae.

\section{EXPERIENCIA Y ACTIVIDAD ADMINISTRATIVA ROMANA EN EL ÁMBITO DE LOS BIENES PÚBLICOS -RES PUBLICAE-}

1. La perfección y organización del sistema jurídico romano, para atender los fines de orden, defensa y, en definitiva, el mantenimiento de la paz social, fundado en los más altos valores de justicia y acomodándose a la expresión de una conciencia política, económica, ética y social, ha otorgado una gran relevancia a los interdictos a lo largo del tiempo, cumpliendo adecuadamente 
la misión protectora y posibilitadora del uso colectivo de los bienes públicos -en términos más recientes, bienes de dominio público-, donde también aflora la voluntad sabia del pueblo romano. Conforme a este planteamiento, resulta una vez más verdaderamente ilustrativo analizar en esta investigación algunas de las órdenes interdictales de mayor interés y de gran arraigo social para el conocimiento de la experiencia administrativa romana, mediante las que se reconoce ampliamente la función social de las res publicae en general y se protege el uso público de los lugares públicos ${ }^{4}$.

2. Cabe recordar ahora el siguiente fragmento - probablemente vinculantede Pomponio: D. 43,7,1 (Pomponius, libro Xxx ad Sabinum): Cuilibet in publicum petere permittendum est id, quod ad usum omnium pertineat, veluti vias publicas, itinera publica: et ideo quolibet postulante de bis interdicitur. En este pasaje, Pomponio, contemporáneo de Salvio Juliano, gran conocedor de la jurisprudencia precedente y del ius bonorarium, pone de relieve que debe permitirse a todo el mundo el uso general de lo que es público, es decir, a todos los miembros de la colectividad. Cabe resaltar también que para cumplir esta finalidad se otorga un interdicto a quien quiera solicitarlo. Utiliza Pomponio como ejemplos de bienes que comprenden las res publicae, las vías públicas y los caminos públicos, si bien, como es sabido, el elenco de cosas públicas es muy amplio. En nuestra opinión cabría añadir que, en relación con las consideraciones precedentemente hechas, resulta indudable que este texto de la compilación justinianea se refiere principalmente a la defensa interdictal propia de los bienes destinados al uso público; aspecto este que se desprende del contenido del precepto al mencionar algunos de los ejemplos -quod ad usum ommnium pertineat (vías públicas, itinera publica).

Respecto a la jurisprudencia -si bien con algunas contradicciones-, encontramos testimonios en las fuentes con una referencia que pone de relieve el amplio significado que se otorga al término publicus, extendido -además de a las cosas pertenecientes al pueblo romano- a las cosas de los municipios. En suma, puede decirse que a todas las cosas que no son de los particulares sino de una colectividad se les llama indistintamente públicas. Un elenco sintetizado -y muy general- de las res publicae in publico usu ${ }^{5}$, según la fuente que estemos

4 Juan Miguel AlburquerQue, La protección o defensa del uso colectivo de las cosas de dominio público. Especial referencia a los interdictos de publicis locis (loca, itinere, viae, flumina, ripae), Prólogo A. Fernández de Buján, Madrid: Dykinson, 2002, reimp. 2010.

5 En relación a las res publicae in publico usu, cfr. entre otros, D. 43,8,2 (Ulpianus, libro LXVIII ad edictum) ${ }_{i}$ D. 18,1,6 pr. (Pomponius, libro IX ad Sabinum); D. 45,1,83,5 (Paulus, libro LXX ad edictum), D. 43,14,1,4-6 (Ulpianus, libro LXVIII ad edictum) $)_{i}$ D. 45,1,137,6 (Venuleius, libro I stipulationum); D. 1,8,4,1 (Marcianus, libro III institutionum); D. 43,8,2,3 (Ulpianus, libro LXVIII ad edictum). Respecto a los demás bienes de titularidad pública que no son de uso público, es decir, los que se conocen como res publicae in pecunia populi, cfr. entre otros, D. 18.1.6 (Pomponius, libro IX ad Sabinum), D. 18,1,72 (Papinianus, libro X questionum); D. 41,1,14 pr. (Neratius, libro V membranorum); C. $11,31,1$; C. 11,31,3. A propósito de la distinción elaborada por diferentes juristas romanos sobre res publicae in publico usu y res publicae in pecunia populi. Cfr., entre otros, D. 43,8,2, 4 y 5 
utilizando, podría quedar así expuesto: las vías y caminos públicos; el foro; las basílicas y las plazas; los campos o solares públicos; los baños y teatros públicos ${ }_{i}$ los lagos de aguas perennes ${ }_{i}$ los estanques de aguas intermitentes y

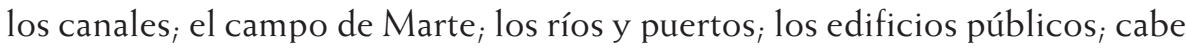
también incluir aquí como cosas públicas las que el hombre constituye y adquieren dicha condición mediante la publicatio ${ }^{6}$. Se correspondería con lo que hoy se denomina afectación de una cosa al uso público. La publicatio era un acto administrativo, cuya competencia estaba expresamente atribuida a magistrados determinados, mediante la cual la cosa quedaba por tanto afectada o destinada al uso público" ${ }^{17}$. En suma, a propósito de nuestra revisión exegética, en consonancia con el estado actual de las fuentes, no sin vacilaciones, y no sin grandes sospechas acerca de la legitimidad de algunos textos, podría decirse que, aunque no se desprende fácilmente de la mayoría de los supuestos mencionados una referencia suficientemente explícita sobre los bienes que componen las res publicae, no parecen existir grandes dificultades que nos impidan decir que los bienes asumen la consideración de públicos -in usu publico- o bien en virtud de un acto de publicatio, o bien por razón de su destino o utilización pública, o bien por causas naturales. Incluso, no debería resultar demasiado extraño, en nuestra opinión, que no encontremos en las fuentes un elenco y una idea con carácter absoluto, suficientemente pormenorizada y homogénea, de estos bienes, porque, probablemente, obedezca a claves históricas completamente enraizadas en la costumbre sobre el usus publicus. Aspecto que en mi opinión puede hacer oscilar-según el clima político, ideológico y jurídico del momento- las diferentes apreciaciones de los juristas en relación a los bienes considerados públicos. No debemos olvidar que la propia idea de la utilitas publica y su evolución ha estado en cada etapa histórica coligada a la noción de res publicae, $y$, aunque no se diera una ley general que contemplara todas las peculiaridades de las res publicae, al menos existen numerosos testimonios en las fuentes de los que se infiere que tuvieron una especial consideración en orden a la captación de la función social de los diferentes bienes públicos.

En Roma, originariamente, se denominaban públicas tanto las res populi romani como los bienes que sirven para atender las cargas de la ciudad, pero como hemos podido observar al analizar las fuentes, en los textos también aparece el contraste diferenciador entre las dos categorías: res publicae in publico usu y publicae in pecunia populi, in patrimonio populi o fiscales. Se podría decir abier-

(Ulpianus, libro LXVIII ad edictum); D. 18,1,6 pr. (Pomponius, libro IX ad Sabinum); D. 18,1,72,1 (Pomponius, libro V membranorum); D. 11,7,8,2 (Ulpianus, libro XXV ad edictum); D. 45,1,137,6 (Venuleius, libro I stipulationum); D. 45,1,83,5 (Paulus, libro LXXII ad edictum).

6 En este sentido cabe recordar el fragmento de Ulpiano, D. 43,8,2,21: .. -qui ius publicandi babuit-. Cfr. D. 41,1,16 - Flor. 6 inst.

7 Antonio Fernández de Buján, Derecho público romano, Pamplona: Civitas-Thomson Reuters, 2015 , pp. 226 ss. 
tamente con la doctrina que esta difusa referencia induce a considerar que no se trataba de una separación demasiado nítida o absoluta. Y, por otra parte, a pesar de la progresiva evolución y maduración de la idea de público, no nos parece admisible negar la convivencia de las categorías referidas, en principio, sin interrupción en el tiempo; pero sin olvidar, claro está, la tendencia que se aprecia en las fuentes a identificar preferentemente las res publicae con las res quae publico usui destinatae. Una afirmación muy reveladora a este respecto nos es transmitida por Ulpiano en D. 43,8,2,5: Así pues, este interdicto se refiere a los lugares que están destinados al uso público, de modo que si en ellos se hiciera alguna cosa que perjudicara a un particular, el Pretor se opondría con su interdicto (Ad ea igitur loca boc interdictum pertinet, quae publico usui destinata sunt, ut, si quid illic fiat, quod privato noceret. praetor intercederet interdicto suo).

3. Los datos que pretendo recopilar ahora corresponden, fundamentalmente, a mandatos interdictales que ponen de relieve de forma especial una pequeña parte de la actividad administrativa desarrollada por los magistrados romanos: los interdictos de publicis locis (loca, itinere, viae, flumina, ripae). Sin embargo, podemos observar que existe una gran dificultad para extraer un criterio sistemático suficientemente pormenorizado que nos permita realizar un estudio sobre estos interdictos (de publicis locis) exento de dificultades. En este sentido, no podemos, por tanto, prescindir de las numerosas interpolaciones que se ha intentado poner de relieve al analizar los diferentes títulos (VII a XV) del libro 43 del Digesto donde aparecen recogidas las disposiciones interdictales objeto de nuestro estudio.

4. Interdictos de lugares públicos (de publicis locis). Del título VIII del Digesto, libro 43, ne quid in loco publico vel itinere fiat (que no se haga cosa alguna en lugar o camino público), cabe resaltar que el fragmento de Ulpiano ocupa casi la totalidad del mismo, si bien existen también unas brevísimas referencias de Paulo. Aunque se trata de un título corto se recogen en él los diferentes pareceres de jurisconsultos de distintas épocas, por lo que puede afirmarse que abarca un espacio de tiempo muy amplio. Así pues, Ulpiano, a lo largo del título VIII, utiliza en varias ocasiones -secundando o no la opinión del jurisconsulto- diferentes criterios, entre los que cabe destacar los de Labeón, Nerva, Ofilio y Aristón, lo que representa el eco de un amplio debate doctrinal a través del cual es posible intentar reconstruir, al menos en líneas generales, el estado de la doctrina en torno a los lugares públicos y a su posible tutela interdictal.

La orden interdictal ne quid in loco publico vel itinere fiat ${ }^{8}$ abarca varias formulaciones, todas ellas con la finalidad de evitar que se haga algo en lugar o camino público, y en general, con la pretensión de proteger todo locus publicus (los solares, los edificios, los campos de cultivo, los caminos públicos y las vías públicas -areae, insulae, agri, itinera publica, viae publica-) de posibles obras no 
autorizadas, así como de perturbaciones o inmisiones que causen algún tipo de daño a alguien o deterioren la vía pública o el camino.

En uno de los textos principales de este título, D. 43,8,2 pr., se recoge lo siguiente: Dice el Pretor: No hagas en lugar público, o introduzcas en este lugar cosa alguna por la cual se le cause a uno algún daño, excepto aquello que por ley, Senadoconsulto, Edicto, o decreto de los Príncipes se te concedió, < pues en este caso> no daré interdicto por lo que < allí > se haya hecho (Praetor ait: ne quid in loco publico facias, inve eum locum immittas, qua ex re quid illi damni detur praeterquam quod lege senatus consulto edicto decretove principum tibi concessum est, de eo quod factum erit interdictum non dabo). El fragmento de Ulpiano nos informa de la orden del pretor por la que se prohíbe que se introduzca algo en lugar público, o que se realice algo que pueda causar daño; excepto que se disponga de alguna autorización legal para ello (ley, senadoconsulto, edicto, decreto de los príncipes).

Este interdicto tiende a impedir todo facere o immittere en un lugar público que pueda ocasionar al demandante algún daño, siempre que la obra no haya sido ya iniciada ${ }^{9}$. Por tanto, la orden interdictal prohibitoria de D. 43,8,2 pr. no puede obligar a quitar lo ya construido, si no concurren por ejemplo los presupuestos del quod vi aut clam. En el fragmento de Ulpiano que estamos comentando aparece prefijado el alcance de las posibles concesiones administrativas por las que se autoriza a hacer o introducir; lo que supone un límite para que se pueda utilizar este interdicto. Ahora bien, cabe decir en vía de principio que siempre que se permite hacer algo en un lugar público debe ser sin perjuicio de nadie, en otras palabras, siempre bajo el presupuesto de que no se cause daño a ningún individuo. Lo que pone de relieve, una vez más, la posición de la autoridad pública o del príncipe en este caso, en relación con la protección tanto de los intereses privados y las res publicae como la garantía de los usuarios potenciales.

Entre los textos más reveladores a nuestros fines podríamos recordar la afirmación de Ulpiano en D. 43,8,2,10: .. cuando se permite hacer algo en un lugar público debe ser sin perjuicio de nadie, y así suele hacerlo el príncipe cuando se solicita poder empezar una obra nueva. Asimismo, podremos recordar el siguiente fragmento, también de Ulpiano, D. 43,8,2,16: si alguien hubiera conseguido del príncipe el derecho de edificar en lugar público sin más determinación, no se debe creer que puede edificar en perjuicio de otro, ni se le concede que lo haga, a no ser que concretamente se lo hubiera permitido el príncipe. Si bien, aunque las posibles concesiones de la autoridad pública en todo lo referente a los lugares públicos se realicen bajo el presupuesto clave -que ningún tercero sufra una desventaja respecto al uso común-, lo que

9 Juan Miguel Alburquerque. La protección o defensa del uso colectivo de las cosas de dominio público, reimpr. 2010, cit., pp. 55 ss. 
constituye el núcleo fundamental de las actuaciones administrativas, es necesario poner de relieve que pueden existir ciertas excepciones, como cuando concretamente se lo hubiera permitido el príncipe -nisi forte quis boc impetravit-.

Partimos de un presupuesto esencial: que no se cause daño a ningún individuo. Se considera que sufre un daño quien pierda una ventaja, un provecho (commodum), cualquiera que fuese en relación al uso público. En el pasaje ulpianeo tomado del mismo libro $^{10}$ y recogido en D. 43,8,2,11 se aborda directamente esta explicación: Se considera que sufre un daño quien pierde alguna ventaja cualquiera que tenía por el uso público (Damnum autem pati videtur, qui commodum amittit, quo ex publico consequebatur, qualequale sit). Unos ejemplos contribuirán a su esclarecimiento. De la casuística emergente de las fuentes podemos traer a colación el comentario de los siguientes textos: "El interdicto se concede en los supuestos en los que se ocasione un entorpecimiento o estrechamiento de las vistas o caminos". El texto de D. 43,8,2,12 se refiere precisamente al supuesto que nos ocupa: Ulpianus, libro XLVIII ad edictum: Por ello, si se entorpecen o estrechan las vistas o caminos, es necesario el interdicto (Proinde si cui prospectus, si cui aditus sit deterior aut angustior, interdicto opus est). Tendrá plena aplicabilidad el interdicto cuando la construcción de un edificio en loco publico provoque una disminución de la luz de la casa del vecino. Así lo recoge expresamente Ulpiano en D. $43,8,2,14$ : Claro que si tal edificio hubiera hecho que tu casa tenga menos luz, sí compete este interdicto (Plane si aedificium boc effecerit, ut minus luminis insula tua babeat, interdictum boc competit $)^{11}$.

5. Prohibición pretoria de hacer o poner en la vía pública o camino público algo que los deteriore o llegue a deteriorar: Interdictum ne quid in via publica itinereve publico fiat, quo ea via idve iter deterius sitfiat ${ }^{12}$. Orden pretoria para restituir lo que se retenga hecho o puesto en la vía o camino público que lo perjudique o pueda perjudicar: Praetor ait: quod in via itinereve publico factum immissum babes, quo ea via idve iter deterius sit fiat, restituas ${ }^{13}$. Orden del magistrado prohibiendo que se impida con violencia a alguien ir o llevar ganado por la vía pública o camino público: Praetor ait: Quo minus illi via publica itinereve publico ire agere liceat, vim fieri veto ${ }^{14}$.

Dentro de la amplísima serie de relaciones susceptibles de protección interdictal, las vías públicas o caminos públicos constituyen un bien destinado al uso público de especial consideración en las previsiones pretorias y jurisprudenciales; incluso suele ser uno de los ejemplos más citados. En la vía pública o camino público, el pretor prohíbe que se haga o ponga algo que los

$1068 \mathrm{ed}$.

11 Juan Miguel Alburquerque. La protección o defensa del uso colectivo de las cosas de dominio público, reimp. 2010, cit., pp. 81 ss.

12 D. $43,8,2,20$.

13 D. $43,8,2,35$.

14 D. $43,8,2,45$. 
deteriore, o llegue a deteriorar ${ }^{15}$. La prohibición de cualquier facere o immittere que pueda ocasionar un perjuicio -afirma Ulpiano- se refiere tanto al momento presente como al futuro (sit fiat... sive statim... sive postea) ${ }^{16}$ y no sólo se dirige contra el autor de la obra que ocasiona el daño, sino también contra el posible poseedor actual, aunque no haya sido el autor material de la misma; que será, como consecuencia lógica, el que podrá restituir a su primer estado con mayor facilidad. Aspecto este que se posibilita como consecuencia de la orden interdictal contenida en D. 43,8,2,35 mediante la cual el pretor otorga un interdicto restitutorio contra aquel que haya hecho o introducido algo en la vía pública que perjudique su funcionalidad; es decir, se extiende por los mismos requisitos que el interdicto prohibitorio. La expresión restituas contenida en la fórmula no solo significa restituir un objeto, sino también la orden de reparar algo en la anterior situación. Con la finalidad de reprimir los actos dirigidos a obstaculizar el uso público, el pretor prohíbe que se impida con violencia el uso normal (ire agere) de las vías públicas ${ }^{17}$. Cabría decir, por tanto, que este interdicto abarca todas las manifestaciones de violencia que se puedan realizar contra la persona con objeto de impedir el uso común de las vías.

En nuestra opinión, no debe olvidarse que, aparte de proteger derechos referentes tanto a la esfera pública como a la esfera privada, la función interdictal ampara, y está al servicio de, la función social del bien público. Si bien esta concepción no implica que desconozcamos la ausencia de homogeneidad en los criterios de valoración de la jurisprudencia, como se desprende de las fuentes. En este sentido, y como ejemplo de lo infructuoso que puede resultar a veces el intento de conciliar las fuentes, cabe hacer referencia al ejemplo de Labeón en D. 43,8,2,26, donde se advierte que quedará obligado por el interdicto el que introdujese una cloaca en vía pública, y por ello esta se hiciera menos útil o practicable -causando un perjuicio al medio ambiente ${ }^{18}$; por lo que puede admitirse que se reconoce aquí una mayor relevancia al bien común mediante la incuestionable tutela del fin colectivo, y la actitud contraria de este mismo jurista en D. 43,8,2,28, frente a Nerva: Labeón tiende a proteger fundamentalmente, en este último supuesto, el fin privado del constructor, aunque con ello se perjudique la vía pública, mientras que la opinión de Nerva, acogida por Ulpiano, se centra principalmente en la tutela de la vía pública.

En relación a los supuestos que amplían el criterio que debe regir a la hora de considerar que una vía ha sido deteriorada (como ejemplos que puedan perjudicar o llegar a deteriorar la vía o el camino público cabe señalar: si la vía era llana y se hace pendiente, lisa y se hace desigual, ancha y se hace más estrecha,

16 D. 43,8,2,31-32. (Ulpianus, LXVIII ad edictum).

17 D. $43,8,2,45$.

18 Renate FisCher. Umweltschützende Bestimmungen im Römischen Recht, Aachen, 1996, pp. $80 \mathrm{~s}$ 
o seca y queda pantanosa o encharcada $)^{19}$, no podemos dejar de pensar, una vez más, que la idea sobre la tutela del bien público había prendido fuertemente en la jurisprudencia mayoritaria, llegando incluso a otorgar prioridad en determinados supuestos a criterios que, para algunos, podrían parecer exagerados (construir un subterráneo y un puente en la vía pública, contra los malos olores en la vía pública); pero, desde una perspectiva general, responden perfectamente a la comprensión del interés público. Así pues, en nuestra opinión, salvo algunas excepciones, resulta implícita la protección del uso colectivo de las cosas de dominio público en la mayoría de las afirmaciones jurisprudenciales; especialmente, cuando hacen referencia a los interdictos de publicis locis (loca, itinere, viae, flumina, ripae). En este sentido, también cabe recordar, por ejemplo, que el pensamiento jurídico se había preocupado, especialmente, de perfilar la extensión de la tutela -en relación a la categoría de las inmisiones-en todo lo que puede afectar a los bienes de uso público ${ }^{20}$. Asimismo, en este ámbito de actuación flexible, con objeto de atender los posibles inconvenientes que pueda provocar el abandono de una obra -sin que alguien retenga lo hecho, caso en el que, claro está, se aplicaría el correspondiente restitutorio ${ }^{21}-$, Ulpiano habla de la competencia de un interdicto vía útil para que se restituya lo que se haya construido en la vía pública ${ }^{22}$.

Podemos observar también en los siguientes capítulos que la polivalencia de la utilidad pública intenta combinar y justificar los respectivos intereses, a los que añadiremos algunas matizaciones. La adecuada sensibilidad del pretor en orden a la captación de la función social de los lugares públicos, y la perspectiva jurisprudencial, más elástica al respecto, hacen que la tutela interdictal cumpla muy atinadamente la misión de garantizar el uso colectivo de los bienes de dominio público en sentido amplio, es decir, tratando de evitar obviamente el uso excesivo de los mismos, y reprimiendo los actos dirigidos a obstaculizar el uso público.

6. Sobre el disfrute de un lugar público: Interdictum de loco publico fruendo ${ }^{23}$. El pretor prohíbe que se impida por la violencia que pueda disfrutar del lugar público, conforme a los términos del arrendamiento, aquel arrendatario, o su socio, que lo tomó en arriendo de disfrute de quien tuviera el derecho de arrendarlo (Praetor ait: Quo minus loco publico, quem is, cui locandi ius fuerit, fruendum alicui locavit, ei cui conduxit sociove eius e lege locationis frui liceat, vim fieri veto). Asimismo se destaca que ha sido propuesto a causa de utilidad pública ${ }^{24}$. Y el mismo Paulo

20 Véase, p. ej., D. 43,8,2,29 (Ulpianus, libro LXVIII ad edictum).

21 D. $43,8,2,35$.

22 D. $43,8,2,39$.

23 D. $43,9,1$.

24 D. $43,8,2,1-1$ 
en este título ${ }^{25}$ añade que suele concederse la colocación, en lugares públicos, de bustos y estatuas que ornen la ciudad.

Como resultado de la pluralidad de significados que puede reflejar el concepto de utilidad pública, aparece justificada la previsión interdictal que hemos abordado en esta sede ${ }^{26}$, si bien, como se observa, puede parecer que no tiene nada que ver con el uso general de los bienes públicos, sino más bien con un posible uso exclusivo del ager publicus ${ }^{27}$ por determinados particulares, mediante el arrendamiento realizado con la autoridad correspondiente; si bien su posible justificación parece evidente: una de las posibles concesiones administrativas suficientemente acreditadas. Es decir, el interdicto de loco publico fruendo no se refiere en sentido estricto a las cosas públicas in publico usu, sino, principalmente, a campos o terrenos públicos (ager publicus) que se conceden en arrendamiento a los particulares y sobre los cuales se puede exigir el correspondiente vectigal.

7. Orden pretoria para facilitar la reparación de las vías o caminos públicos. En efecto, el pretor prohíbe que se impida por la violencia que el demandante pueda restaurar o reparar la vía o el camino público con tal de no deteriorarlos. D. 43,11,1 pr. ${ }^{28}$ : Praetor ait: Quo minus illi viam publicam iterve publicum aperire reficere liceat, dum ne ea via idve iter deterius fiat, vim fieri veto. Así pues, siempre que bajo esta presunción de reparar la vía o el camino no se produzca ningún tipo de deterioro que pueda alterar su funcionalidad originaria. El significado de deterius fieri puede ser amplísimo ${ }^{29}$ (se entiende que se perjudica la vía cuando se inutiliza su uso para pasar o conducir, es decir, si era llana y se hace pendiente, si era lisa y se hace desigual o áspera, o si de ancha pasa a ser más estrecha, y, finalmente, si la vía estaba seca y se hace encharcada o pantanosa; incluso podríamos añadir en este elenco de actividades que pueden causar un perjuicio a la vía el hecho de arar la misma ${ }^{30}$ itambién podríamos recordar, por extensión, respecto de las vías públicas del interior de la ciudad, cuyo cuidado estaba reservado, principalmente, a los ediles, que el deterioro de las mismas lo puede producir tanto la acción de cavar en ellas como el socavarlas ${ }^{31}$ ). La orientación que este jurisconsulto atribuye a la expresión aperire viam ${ }^{32}$ se ajusta al de resta-

D. $43,8,2,2$.

D. 43.9, interdictum de loco publico fruendo.

Lo que Cicerón, De lege agrar. Contra Ballum. 2.29, denominaba "la cabeza de las fortunas públicas": ... caput publicae pecuniae. Consecuencia lógica de las grandes ganancias que obtenía el Estado mediante el arrendamiento habitual del ager publicus.

Ulpianus, libro LXVIII ad edictum.

Por ejemplo, D. 43,8,2,31-32 (Ulpianus, libro LXVIII ad edictum).

Por ejemplo, D. 43,11,3,1 (Paulus, libro I Sententiarum): Qui viam publicam exaraverit, ad munitionem eius solus compellitur.

1 Por ejemplo, D. 43,10,2 (Papiniano): <Curam autem babeant, ut nullus effodiat vias, neque subruat, neque construat in viis aliquid... $>$.

2 Por ejemplo, D. 43,11,1,1 (Ulpianus, libro LXVIII ad edictum): Viam aperire est ad veterem altitudinem latitudinemque restituere. sed et purgare refectionis portio est: purgare autem proprie dicitur ad libramentum 
blecimiento de la vía en su altura y anchura primitiva. Purgare viam se entiende como el restablecimiento de la vía a su propio nivel, limpiando o quitando lo que hubiese sobre ella. Como puede observarse, las dos operaciones referidas constituyen aspectos diversos de lo que supone el mantenimiento. De las referencias que nos proporciona este jurista se puede aducir que del texto surge claramente la tendencia a incluir en el concepto de reparación todo aquello que pueda resultar beneficioso para el mantenimiento óptimo de las vías y de los caminos públicos. En suma, se vislumbra también, en esta ocasión, lo que podría considerarse progresivamente como un principio general por constituir una de las tendencias jurisprudenciales más frecuentes en orden a la máxima protección en relación a los bienes de dominio público con la principal finalidad de la libre utilización por todos.

Nos parece interesante recordar que muchas de las facultades expectantes a los ciudadanos sobre las cosas públicas no están subordinadas a la actuación previa de los órganos competentes, pero sí están condicionadas expresa o tácitamente las posibilidades de su ejercicio a la utilidad pública, con objeto de impedir aquellas actividades que puedan menoscabar el uso general de los bienes de dominio público.

8. Sobre los ríos públicos: Que no se haga en un río público ni en su orilla algo que perjudique la navegación, constituye el enunciado del título XII del libro 43 del Digesto, que trata sobre los ríos públicos, donde encontramos el Interdictum ne quid in flumine publico ripave eius fiat, quo peius navigetur. En D. 43,12,1 pr., el pretor prohíbe que se haga o ponga en un río público o en su orilla cualquier cosa que pueda entorpecer el estacionamiento o tránsito de la navegación: Ait praetor: Ne quid in flumine publico ripave eius facias, ne quid in flumine publico neve in ripa eius immitas quostatio iterve navigio deterius sit, fiat.

La visión romana respecto a las aguas públicas y privadas es amplísima. En materia de aguas, queremos hacer especial hincapié en la demostración de cómo la sensibilidad romana trasciende a las legislaciones actuales. En este sentido, nos parecen muy acertados los escritos de Gallego Anabitarte ${ }^{33}$ sobre el derecho de aguas en España, donde se pone de relieve que "es un hecho extraordinario, pero el derecho romano de las aguas ha estado y está presente en todos los estudios de aguas del derecho occidental. El tronco común del que salen el actual Derecho francés, anglosajón, alemán y español es el Derecho Romano y muy en concreto determinadas y específicas regulaciones de la Instituta de Justiniano y del Digesto".

La distinción entre aguas públicas y privadas ha dado lugar a numerosas tentativas de conciliación, que ahora no es preciso recordar en profundidad. 
Nosotros destacaremos brevemente la disciplina jurídica que afecta especialmente a los ríos públicos, donde también observaremos los criterios generales que se desprenden de la condición natural y de la valoración económico-social para fijar la publicidad o el carácter privado de los cursos de agua.

9. Como ya hemos referido, la sucesiva intervención pretoria, en consonancia con las concepciones sociales respecto al uso común que se debe otorgar a los ríos públicos, se ve reflejada en las disposiciones introducidas en los títulos 12-15 inclusive del libro 43 del Digesto (XII, De fluminibus, ne quid in flumine publico ripave eius fiat, quo peius navigetur-sobre los ríos públicos: Que no se haga en un río público ni en su orilla algo que perjudique la navegación-; XIII, Ne quid in flumine publico fiat, quod aliter aqua fluat, atque uti priore aestate fluxit-que no se haga en un río público algo por lo que el agua fluya de otra forma que en el anterior estío-; XIV, Ut in flumine publico navigare liceat-que se pueda navegar por un río público-; $\mathrm{XV}$, De ripa munienda -sobre el interdicto para reparar la orilla-).

El motivo que inspira estos interdictos lo constituye, en definitiva, la tutela de la navegación fluvial. En la primera disposición interdictal respecto a los ríos se prohíbe todo aquello que de alguna forma pueda entorpecer, perturbar o dificultar la libre navegación fluvial, consentida a todos los posibles usuarios, reprimiendo mediante este interdicto todas las actividades mencionadas que puedan menoscabar el buen estado de los ríos públicos para la navegación. De los 21 parágrafos transmitidos por Ulpiano en el párrafo primero del libro que estamos comentando ${ }^{34}$, se desprenden datos de especial relevancia. Comentaremos a continuación algunos ejemplos. Nuestro jurista nos dice que los principales elementos diferenciadores entre los arroyos y los ríos, los constituyen el tamaño o magnitud y la estimación de los vecinos ${ }^{35}$. Es decir, en nuestra opinión, extiende la condición abstracta: tamaño, magnitud, medidas, sin precisiones demasiado nítidas, y la consideración que de esa corriente de agua tengan los habitantes de los alrededores, o los que habitan a lo largo de la orilla; abstracción que nos parece, quizá, demasiado compleja, pero que de alguna forma parece que intenta ajustarse a los rasgos que denota la nueva concepción que, como hemos señalado más arriba, destaca, como algo más aconsejable para la época, según las previsiones de la jurisprudencia clásica, deducir el criterio de la publicidad de la naturaleza física de los cursos de agua integrada por la valoración social, o, como señala Fernández de Buján ${ }^{36}$, los que tuvieran reconocida tal cualidad en función de las especiales circunstancias geográficas o de singular valoración social. La existencia de ríos públicos y ríos privados, así como el criterio de la perennidad como elemento diferenciador, aparecen en D. 43,12,1,3: Hay ríos que son públicos y otros que no lo son. 
Casio define el río público como aquel que es perenne, esta opinión de Casio, que también aprueba Celso, parece ser la más probable. El jurista acude al sistema de citas para intentar establecer con mayor acierto la connotación más específica que pueda determinar, con aquiescencia jurisprudencial histórica, la diferencia entre río público y río privado. No obstante, aunque Ulpiano asume la opinión de Casio, discípulo de Masurio Sabino, avalada por el conocido proculeyano Celso (filius), miembro del consilium de Adriano, en la que se justifica la publicidad de los ríos con la perennidad, como veremos infra, no se desprende absolutamente de sus titubeos o indecisiones: videtur esse probabilis. La perennidad resulta, a los ojos de cualquier intérprete, la causa física o geográfica que parece justificar la publicidad de los ríos, sin embargo, como acertadamente escribe Scialoja ${ }^{37}$, la definición de río público basada en la perennidad no debe considerarse como una cosa absolutamente cierta y universalmente admitida. Así pues, a nuestro modo de ver, en orden a la concepción clásica de río público, cabría decir que Ulpiano parece que adopta una postura ambigua no exenta de prevención. Quizá el planteamiento de Ulpiano, siguiendo un criterio excesivamente clásico (la perennidad), lo que perseguía era mantener una idea simplificadora de la publicidad fluvial, que no se apartara en exceso de las afirmaciones jurisprudenciales que encuadraban a los ríos dentro de los bienes de uso público, como las vías públicas. Lo que le impedía a este jurista conformar un criterio más pormenorizado que pudiera contribuir a cercenar de alguna forma el libre uso y aprovechamiento de los mismos; si bien, a pesar de las conjeturas que hemos expresado, tendríamos que revisar sus explicaciones, pues la ambigüedad, a nuestro modo de ver, persiste ${ }^{38}$.

Teniendo presente cuanto se ha dicho, no nos parece acertado negar que el criterio de la perennidad, desde Casio (siglo I), haya prevalecido como el más adecuado para la jurisprudencia posterior, si bien en tan largo proceso (hasta Ulpiano, siglo III) podría echarse de menos que no se haya ajustado nítidamente a los perfiles más característicos de una época más avanzada, donde parece que juegan un papel muy relevante otras estimaciones que podrían ser más aconsejables desde la perspectiva jurídica, no desde la visión exclusivamente natural, para determinar la publicidad de un río; especialmente, teniendo en cuenta que se trata de un criterio geográfico, bastante simple y obvio a la hora de definir un río -que podría considerarse como una tentativa incompleta-, pero que la aparente simplicidad o excesiva clasicidad del mismo puede tener una trascendencia jurídica enorme. Si bien no tiene por qué tratarse de fases contradictorias, pues revelan una misma voluntad unificadora. Asimismo, en nuestra opinión, cabría añadir que aunque la navegabilidad sea tutelada de 
forma precisa en la mayoría de los textos interdictales y jurisprudenciales ${ }^{39}$, como ya dijimos, encontramos referencias suficientemente explícitas que nos impiden afirmar que pueda constituir el elemento complementario clave para llegar a conclusiones que nos induzcan a pensar, con parte de la doctrina, que constituye el segundo aspecto condicionante para determinar la publicidad de los ríos.

Labeón intenta extender la aplicación de este interdicto vía útil, incluso a los ríos no navegables, como nos dice Ulpiano en D. 43,12,1,12: Este interdicto afecta sólo a los ríos que son navegables, no a los otros. Aunque escribe Labeón que no es injusto que competa también un interdicto útil cuando se hace algo en un río no navegable de suerte que este quede seco o se entorpezca el curso de su agua, concebido así: que no se le impida con la violencia que pueda quitar, demoler, limpiar o restituir conforme al arbitrio de un hombre recto aquella obra hecha en el cauce del río o en su orilla que entorpezca o pueda entorpecer el tránsito o la corriente del río.

Convendría retomar ahora la disposición interdictal objeto de nuestro análisis ${ }^{40}$, que comienza diciendo: No hagas en río público o en su orilla... Ne quid in flumine publico ripave eius facias... Indudablemente el análisis explicativo de Ulpiano continúa reflejando una cierta complejidad. Por una parte, el jurisconsulto ha intentado suplir la incertidumbre de la publicidad de los ríos acogiendo, con ciertas reservas, las afirmaciones clásicas señaladas precedentemente, pero también es consciente de que el estudio de los elementos que componen un río, tanto público como privado, puede dar lugar a posturas contrapuestas sobre la publicidad de los mismos. Ciertamente, llama la atención, asimismo, que el pretor prohíba que se haga o introduzca en río público o en su orilla alguna cosa que pueda perjudicar la navegación, matizando exclusivamente en río público o en su orilla.

Como primera observación que se puede plantear a simple vista, podríamos preguntarnos por qué el magistrado destaca separadamente río público o su orilla. Cuando Ulpiano ${ }^{41}$ aborda la definición de orilla parece referirse a lo que contiene al río en su natural vigor, es decir, al flujo natural de su corriente o al nivel habitual del agua del río, en suma, a su curso normal. El jurista pone un ejemplo que sirve para advertir lo absurdo que sería establecer una referencia diferente ante una posible inundación por una crecida del Nilo, a causa de la lluvia o el mar, que posteriormente se retira a su cauce habitual, por lo que se puede decir abiertamente (ripas non mutat). Sabemos que la orilla es uno de los elementos propiamente constitutivos de los ríos. A este propósito, cabría añadir que también el cauce del río forma parte imprescindible de la natural 
conformación de los mismos, ut alveum fluminis veterem populi romani, como decían los gromáticos. En este sentido, cabría preguntarse por qué no alude el pretor expresamente al cauce del río, y sí, simplemente, a su orilla. En un principio, podría pensarse que la cuestión se resuelve fácilmente por considerar que se trata de uno de los componentes más específicos del río, por lo que en todo momento comparte la publicidad en sentido estricto -estimación que refuerza Ulpiano diciendo que es imposible que el cauce de un río público no sea público-, y las orillas se pueden prestar más a opiniones controvertidas, pero que en definitiva, si bien se puedan considerar privadas para algunos, lo que no se niega rotundamente es que están destinadas al uso público como veremos infra. En suma, cabría pensar que el magistrado entiende que el cauce es uno de los elementos que no permite diferenciación alguna de la corriente de agua fluvial que lo recorre, y que la orilla debe ser expresamente protegida, por ser un elemento que también determina la configuración del río. En efecto, en el análisis de los diferentes elementos propios de un río, a nuestro juicio, no deberíamos excluir las orillas, sin dejar de aceptar, desde el principio, que pueden encontrarse inmersas en una situación ambigua, pero que podría resolverse con facilidad si atendemos al uso general admitido; independientemente de su verdadera condición jurídica.

Labeón concede una atención especial al mar y sus costas. Si se perjudica el usus publicus por cualquier tipo de obra o por una inmisión en el mar o su litoral, que entorpezca el tránsito de las naves, la estancia o la utilización del puerto, el jurista augusteo no duda en señalar la aplicabilidad de este interdicto $^{42}$. Labeón señala las modificaciones propias que hay que introducir en su redacción -sin innovaciones bruscas en la sustancia- en un pasaje contenido en D. $43,12,1,17^{[43]}$ : Si se hace algo en el mar, dice Labeón que compete el interdicto con las siguientes modificaciones en su redacción: $<<\ldots$ en el mar o en su orilla nada... $>>$ y $<<\ldots$ que pueda entorpecer el uso de un puerto, el estacionamiento y el tránsito del navigio $>>$ ( $S i$ in mari aliquid fiat, Labeo competere tale interdictum: ne quid in mari inve litore quo portus statio iterve navigio deterius fiat). Como puede verse, Labeón admite la aplicación de nuestro interdicto a todo lo concerniente al mar o sus orillas. Ante la incuestionable importancia que tienen los ríos (con sus orillas) y los mares (con sus costas), como soporte y medio de transporte funcional, y como fuente de riqueza en sí mismos, podría resultar innecesario razonar en términos de público o privado para adaptar la aplicación interdictal, teniendo presente que se encuentran en una situación abierta a todos los posibles usuarios. El intento de conciliar los criterios rectores sobre el interés público y el particular no deja lugar a grandes dudas. Si nos centramos ahora, simplemente, pero con carácter exclusivo, en las cuatro 
referencias directas en relación al mar (dos de Ulpiano, una de Celso y otra de Scevola), que aparecen en el título ocho (ne quid in loco público...), del libro 43 del Digesto, observamos, a primera vista, que se puede favorecer el carácter privado de la construcción en el mar, siempre que no resulte nadie perjudicado, como hace notar Ulpiano, expresamente, aludiendo al interdicto vía útil ${ }^{44}$ es posible la aplicación de la acción de injurias, como señala Ulpiano, para los supuestos de otros usos no encuadrados en la previsión del interdicto ${ }^{45}{ }_{i}$ Celso destaca el uso común del mar, siempre que no se entorpezca verdaderamente el uso de la costa o el mar ${ }^{46}$; Scevola asume la licitud de la construcción en la costa, siempre que no se impida el uso público de la misma ${ }^{47}$. Situándonos ahora en el título 12 (de fluminibus), del mismo libro 43, no cabe duda de que la búsqueda del aprovechamiento y conservación de los ríos públicos y de los mares persiste en los juristas, como se desprende del fragmento ulpianeo que recoge la afirmación de Labeón que hemos comentado admitiendo la competencia de nuestro interdicto respecto al mar y sus orillas ${ }^{48}$.

En virtud de una disposición introducida por el pretor, que nos transmite Ulpiano, en D. 43,12,1,19, podemos hablar de un segundo interdicto restitutorio: Dice asimismo el Pretor, restituirás lo que retengas hecho en un río público o en su orilla o lo puesto en él o en su orilla que entorpezca o pueda entorpecer el estacionamiento o tránsito del navigio (Deinde ait praetor: Quod in flumine publico ripave eius fiat, sive quid in id flumen ripamve eius immissum babes, quo statio iterve navigio deterior si fiat, restituas). Si nos ajustamos al conjunto literal del fragmento, no tendríamos que plantearnos ninguna observación, pues como afirma Ulpiano, el pretor ordena la restitución de todo lo que se retenga hecho, o se haya puesto, en un río público o en su orilla, que entorpezca o pueda entorpecer el estacionamiento o el tránsito del navío o barca (es decir, incluyendo por tanto las embarcaciones grandes - naves- y pequeñas -barcas). La situación puede ser análoga para el mar: Restituirás lo que retengas en el mar o en su litoral o lo puesto en él [...]. La popularidad de nuestro interdicto es menos discutida por la doctrina.

Así pues, si en el mar se hiciera alguna cosa, como afirma Labeón, compete el interdicto. Las modificaciones que tienen que introducirse en la redacción, como hemos indicado, son: $<<\ldots$ en el mar o en su orilla nada... $>>$ y $<<$ que pueda entorpecer el uso de un puerto, el estacionamiento o el tránsito del navío o barca > >.

10. XIII, Ne quid in flumine publico fiat, quod aliter aqua fluat, atque uti priore aestate fluxit-que no se haga en un río público algo por lo que el agua fluya de otra

D. $43,8,2,9$.

D. $43,8,3$.

D. $43,8,4$.

D. $43,12,1,17$.
} 
forma que en el anterior estío-. D. 43,13,1 pr. ${ }^{49}$ : Ait praetor: In flumine publico inve ripa eius facere aut in id flumen ripamve eius immittere, quo aliter aqua fluat, quam priore aestate fluxit, veto. Esta orden pretoria se refiere, abiertamente, a los ríos públicos, sean o no navegables, como nos indica la reflexión ulpianea: D. 43,13,1,2: Pertinet autem ad flumina publica, sive navegabilia sunt sive non sunt.

El pretor no intenta proteger mediante este interdicto todos los actos que puedan perjudicar el río en sí, sino, con carácter especial, todas aquellas actividades que puedan producir el menoscabo del mismo, por derivaciones ${ }^{50}$ no permitidas (lo que puede alterar su corriente habitual), o mutaciones arbitrarias del cauce, ocasionando un grave perjuicio a los vecinos. En este sentido parece pronunciarse Ulpiano en D. 43,13,1,1: Con este interdicto provee el Pretor para que los ríos no aumenten por derivaciones no permitidas que se hagan a su corriente o que se mude el cauce con perjuicio para los vecinos (Hoc interdicto prospexit praetor, ne derivationibus minus concessis flumina excrescant vel mutatus alveus vicinis iniuriam aliquam adferat). A modo de síntesis, y tras un análisis de los mandatos pretorios y previsiones jurisprudenciales que se contemplan en el conjunto del título XIII, cabe resaltar la habitual coexistencia de la pareja de interdictos, vetatorio ${ }^{51}$ y restitutorio ${ }^{52}$. Ambos encuentran su ámbito de aplicación en los ríos públicos, sean o no navegables, y sus orillas.

11. XIV, Ut in flumine publico navigare liceat-que se pueda navegar por un río público-. La preocupación pretoria por garantizar la navegación efectiva en los ríos públicos vuelve a ponerse de manifiesto en este fragmento, que no trata de valorar ahora las consecuencias perjudiciales de un facere o immitere, sino, preferentemente, impedir el comportamiento de un tercero que mediante la violencia imposibilite el uso lícito general. D. 43,14,1 pr. ${ }^{53}$ : Prohíbo que se impida violentamente al demandante pasar con barco o balsa por un río público y cargar o descargar en la orilla. Asimismo daré interdicto para que se pueda navegar por lago, presa o estanque público (Praetor ait: Quo minus illi in flumine publico navem ratem agere quove minus per ripam onerare exonerare liceat, vim fieri veto. item ut per lacum fossam stagnum publicum navigare liceat, interdicam).

Al tratarse de un interdicto prohibitorio se tiene que pensar fundamentalmente en el daño inminente o futuro que se pretende impedir, considerando que este interdicto carece de fórmula restitutoria. La intervención del pretor protege tanto la conducción o paso (agere) libre de las naves y barcas, como la carga y descarga (onerare, exonerare) de los fletes en la orilla del río público. Asimismo, como puede observarse, de la redacción interdictal se desprende

50 Juan Miguel Alburquerque, La protección o defensa del uso colectivo de las cosas de dominio público, reimp. 2010, cit.

51 D. $43,13,1 \mathrm{pr}$

52 D. $43,13,1,11$.

53 Ulpianus, libro LXVIII ad edictum. 
que la prohibición pretoria se extiende a los lagos (contienen agua de forma permanente), estanques (contienen generalmente agua estancada, que suele recogerse en invierno) o presas públicas (receptáculo de agua hecho a mano, es decir, construido de forma artificial).

12. XV, De ripa munienda -sobre el interdicto para reparar la orilla-. El interdicto prohibitorio de ripa munienda propuesto por el pretor tiene la siguiente formulación: Dice el Pretor: Prohíbo que se impida violentamente al demandante el hacer alguna obra en un río público o en su orilla para poder proteger ésta o el terreno vecino, siempre que no se estorbe con ello la navegación y se te dé promesa, con o sin garantía <según las personas $>$, de indemnizar el daño temido conforme al arbitrio de un hombre recto, por un plazo de diez años, o no haya dejado por él de darse aquella promesa ${ }^{54}$.

La condición principal e inexcusable para proteger a quien quiera reparar la orilla de un río público la representa de nuevo la viabilidad de la navegación. Por tanto, si alguna persona pretende reparar la orilla obstaculizando la navegación no podrá invocar este remedio interdictal, pues, como añade Ulpiano en D. 43,15,1,2, sólo deben tolerarse las reparaciones que no van a constituir impedimento para la navegación: ... illa enim sola refectio toleranda est, quae navigio non est impedimento.

13. A modo de observación conclusiva, podemos afirmar que las fuentes analizadas avalan nuestra convicción sobre la evolución positiva de las perspectivas pretorias y jurisprudenciales acerca del reconocimiento de la función social de los bienes destinados al uso público. Puede observarse que proporcionan una tutela y una garantía preferente al uso general de los bienes públicos, y aunque las iniciativas tutelares por la vía interdictal no hayan conseguido desprenderse en términos absolutos de la interdependencia recíproca, entre el interés privado y el interés público, cuando media un bien público, o representa el punto de partida, con todas sus peculiaridades, la suma de motivaciones jurisprudenciales y las perspectivas de las previsiones interdictales contribuyen a superar los flecos del confusionismo -o la ambigüedad propia de las imbricaciones conceptuales existentes en este tipo de bienes-, para alcanzar una defensa más apropiada a la idea de uso colectivo. No obstante, si no podemos hablar claramente de un concepto unívoco o determinante para trazar los perfiles diferenciadores entre las diversas categorías de res publicae, en relación al análisis de la noción de usus publicus o communis, sí podemos compartir con Schiavon ${ }^{55}$ que se trata de un "paradigma orientativo della giurisprudenza romana elaborato a partire dalla predisposizione da parte del pretore di una serie di rimedi

55 Alvise Schiavon. "Storia dei dogmi e individualità dei giuristi nell'interpretazione della categoria delle res communes omnium", en Storia dei dogmi e individualità storica dei giuristi romani, a cura di C. Baldus, M. Miglietta, G. Santucci, E. Stolfi, Università degli Studi di Trento, 2012, pp. 620 ss. 
processuali di natura interdittale e usato per orientare la giurisprudenza nella costruzione e utilizzazione di concetti giuridici". En suma, una orientación pretoria fundamental que justifica, a nuestro modo de ver, la predisposición jurisprudencial más efectiva para preservar el uso común, principio rector de la verdadera función social de los bienes públicos.

\section{BIBLIOGRAFÍA}

Adame, Jorge. "El procedimiento 'ex interdicto' en el derecho romano clásico", Revista de Investigaciones Jurídicas (Escuela Libre de Derecho), México, 1978, pp. 255 ss.

Alburquerque, Juan Miguel. La protección o defensa del uso colectivo de las cosas de dominio público. Especial referencia a los interdictos de publicis locis (loca, itinere, viae, flumina, ripae), Prólogo A. Fernández de Buján, Madrid: Dykinson, 2002, reimp. 2010.

Alburquerque, Juan Miguel. "Interdictum ne quid in flumine publico ripave eius fiat (D. 43.12.1 pr.)», en SDHI, 71, 2005, pp. 193-269.

Alburquerque, Juan Miguel. "La interrelación de interés público, interés común e interés privado en la noción de utilitas publica", RGDR 25 (acceso restringido www. iustel.com), 2015, pp. 1 ss.

Berger, Adolf. Interdictum, en PWRE IX, pt. II, 1916, pp. 1609 ss.

Biscardi, Arnaldo. "Sul regime delle locazioni amministrative in diritto romano", en Studi in onore di A. Amorbt 1, Milano, 1982.

Branca, Giuseppe. Le cose extra patrimonium humani iuris, Trieste, 1940.

Bonfante, Pietro. Corso di diritto romano II, La proprietà, Milano, 1966.

CAPOgrossi Colognesi, Luigi. La struttura della proprietà e la formazione dei iura praediorum nell'età repubblicana, II, Milán, 1976.

Capogrossi Colognesi, Luigr. "Interdetti", ED, 21, 1971, pp. 919 ss.

Giannini, Massimo Severo. Diritto amministrativo, 3. ${ }^{\text {a }}$ ed., Milano, 1993.

Di Porto, Andrea. La tutela della salubritas fra editto e giurisprudenza I. Il ruolo di Labeone, Milano: Giuffrè, 1990.

Di Porto, Andrea. "Interdetti popolari e tutela delle res in usu publico", Atti del seminario torinese di Diritto e Processo nella esperienza romana, Napoli: Università di Torino, pp. 483 ss. 
Fernández de Buján, Antonio. Derecho público romano, Pamplona: Civitas-Thomson Reuters, 2015.

Fernández de Buján, Antonio. Derecho administrativo bistórico, Santiago de Compostela: Xunta de Galicia, 2005.

Fernández de BujÁn, Antonio. Hacia un derecho administrativo y fiscal romano, dir. coed. A. Fernández de Buján, G. Gerez Kraemer y B. Malavé, Madrid-Valencia: Dykinson, 2011.

FERnÁNDEZ de BujÁn, ANTONIO. Hacia un derecho administrativo y fiscal romano II, dir. coed. A. Fernández de Buján y G. Gerez Kraemer, Madrid-Valencia: Dykinson, 2013.

FERNÁNDEZ DE BujÁN, ANTONIO. Hacia un derecho administrativo y fiscal romano III, dir. coed. A. Fernández de Buján y G. Gerez Kraemer, Madrid-Valencia: Dykinson, 2016.

Fernández de Buján, Antonio. "Perspectivas de estudio en temática de derecho administrativo romano, surgidas a tenor del pensamiento y de la obra de Giambattista Impallomeni", Index 26, 1998, pp. 463 ss.

FERnÁNDEZ de BujÁn, Federico. "Roma conforma España", en Hacia un derecho administrativo y fiscal romano II, Madrid: Dykinson, 2013, pp. 191 ss.

FisCHER, Renate. Umweltschützende Bestimmungen im Römischen Recht, Aachen, 1996.

Gallego Anabitarte, Alfredo; Menéndez Rexach, Ángel y Díaz Lema, José. El derecho de aguas en España, Madrid, 1986.

Gerez Kraemer, Gabriel. El derecho de aguas en Roma, Prólogo A. Fernández de Buján, Madrid: Dykinson, 2008.

Gerez Kraemer, Gabriel. "Los principios generales del derecho administrativo en el derecho romano y el derecho español", Revista General de Derecho Romano (acceso restringido www.iustel.com) 24, 2015, pp. 1 ss.

Grosso, Giuseppe. Corso di diritto romano. Le cose, Torino, 1941.

JimÉNEZ, CARMEN. El régimen jurídico de las relaciones de vecindad en derecho romano, Córdoba: UCO-Cajasur, 1999.

Lenel, Otto. Das Edictum Perpetuum. Ein Versuch zu seiner Wiederherstellung, 3. a ed., Leipzig, 1927.

Musumeci, Nello. "Tutela dell'ambiente e diritto romano", Index, 20, 1992, p. 567.

Novkirishka, Malina. De iure publico, Studi di diritto publico romano, Prólogo A. Fernández de Buján, Sofía: Ciela, 2013. 
Parada VázQuez, Ramón. Derecho administrativo. Bienes públicos y urbanismo, III, 2. a Madrid, 1989.

Parejo Alfonso, Luciano. "Dominio público: un ensayo de reconstrucción de su teoría general", RAP, vol. III, 1983, pp. 100 ss.

Ponte, Vanessa. Régimen jurídico de las vías públicas en derecho romano, Prólogo A. Fernández de Buján, Madrid: Dykinson, 2005.

Ponte, VAnessa. "La regulación de las vías públicas en el seno del derecho administrativo romano", en Hacia un derecho administrativo y fiscal romano, Madrid: Dykinson, 2011, pp. 369 ss.

Riccobono, Salvatore. "Il problema della ricostruzione delle strutture amministrative romane", en Synteleia, V. Arangio Ruiz, Napoli, 1964, pp. 663 ss.

Ruiz Pino, Salvador y Alburquerque, Juan Miguel. "Algunas notas referentes a la experiencia administrativa romana de protección de los recursos naturales", en Hacia un derecho administrativo y fiscal romano, Madrid: Dykinson, 2011, pp. 409 ss.

Ruiz Pino, Salvador. "La protección de los recursos naturales y de la salubritas en Roma", en Hacia un derecho administrativo y fiscal romano II, Madrid: Dykinson, 2013, pp. 413 ss.

Scherillo, Gaetano. Lezioni di diritto romano. Le cose, I, Milano, 1945.

Schiavon, Alvise. "Storia dei dogmi e individualità dei giuristi nell'interpretazione della categoria delle res communes omnium", en Storia dei dogmi e individualità storica dei giuristi romani, a cura di C. Baldus, M. Miglietta, G. Santucci, E. Stolfi, Università degli Studi di Trento, 2012, pp. 593 ss.

Scialoja, VitToRio. Teoria della proprietà nel diritto romano, vol. I, Roma, 1928 pp. 231 ss.

Trisciuoglio, Andrea. "Consideraciones generales sobre la tutela de las res publicae y de sus usos en la experiencia romana", en Hacia un derecho administrativo y fiscal romano, Madrid: Dykinson, 2011, pp. 151 ss.

Ubbelohde, August. Die Interdikte zum Schutze des Gemeingebrauchs, Erlangen, 1893.

Zoz, Maria Gabriella. Riflessioni in tema di res publicae, Torino: Giappichelii, 1999. 